\title{
Association between artificially sweetened beverages consumption and changes in body mass index among children
}

\author{
Muhammad Bilal Arshad ${ }^{a}$, Muhammad Usman Sheikh ${ }^{b}$, Muhammad Afzalc $^{c}$ Aneela Amjad ${ }^{\text {, }}$ \\ Shahzeb Patolie, Muhammad Behzad Salahuddin ${ }^{\mathrm{f}}$ \\ ${ }^{a}$ Assistant Professor, Community \& Preventive Dentistry Department, Avicenna Dental College, Lahore. \\ ${ }^{b}$ Associate Professor, Department of Community Medicine, Avicenna Medical College, Lahore. \\ 'Senior Registrar, Department of Medicine, Avicenna Medical College, Lahore. \\ ${ }^{\mathrm{d} A s s o c i a t e}$ Professor, Department of Oral Medicine \& Diagnostics, Sharif Medical \& Dental College, Lahore. \\ ${ }^{\mathrm{e} A s s o c i a t e}$ Professor, Community \& Preventive Dentistry, Avicenna Dental College, Lahore. \\ ${ }^{\mathrm{f}}$ Associate Professor, Department of Oral Pathology, Avicenna Dental College, Lahore. \\ *Corresponding author: mbilalarshad786@hotmail.com
}

\section{ABSTRACT}

BACKGROUND \& OBJECTIVE: Poor food quality and choices are a major concern in the modern life style and increased consumption of sweetened and artificially sweetened beverages have been implicated as contributing factors for obesity. The objective of this study is to determine the association between the consumption of artificially sweetened beverages and changes in body mass index among children.

METHODOLOGY: Data on the consumption of artificially sweetened beverages consumption and BMI for 13,287 children was analyzed for exposure and outcome from Millennium Cohort Study (MCS). The association between frequency of ASB consumption and BMI was quantified using demographics and linear regression analysis. The linear regression analysis was done adjusting demographic, socioeconomic variables and confounding factors of frequency of physical activity. Regression analysis was conducted using survey weights to account for the complex sampling design.

RESULTS: Adjusted linear regression for demographical and socioeconomic variables showed that more frequent consumption of ASB was associated with a significant increase in BMI. As the frequency of ASB increased, BMI significantly increased by $0.69-1.06$ units in categories $(p<0.01)$. Regression analysis adjusted for frequency of physical activity also showed an increase of BMI by 0.36 units $(\mathrm{p}<0.01)$ with the highest frequency of ASB consumption.

CONCLUSION: Higher consumption of artificially sweetened beverages causes an increase in BMI among UK children. KEYWORDS: Artificially sweetened beverages, Artificial sweeteners, BMI, Childhood obesity, Obesity.

\section{INTRODUCTION}

Obesity is defined as" A medical condition in which excess body fat has accumulated to the extent that it may have an adverse effect on health, leading to reduced life expectancy and/or increased health problems" ${ }^{[1]}$. Obesity has become a phenomenon and public health problem observed worldwide and its ever-increasing global prevalence has made it a pandemic ${ }^{[2,3,4]}$. An adult is considered to be obese if the BMI (Body Mass Index), which is calculated as weight/ height 2 , overpasses $30 \mathrm{~kg} / \mathrm{m} 2$. A BMI of between $25 \mathrm{~kg} / \mathrm{m} 2$ and $30 \mathrm{~kg} / \mathrm{m} 2$ is classified as overweight ${ }^{[5]}$. Overweight and obesity in children are measured by different criteria. These include BMI adjusted for both age and sex, a measure that has become more popular recently in assessing childhood obesity. Other measures are bio-impedance, skinfold thickness, waist to hip ratio, waist circumference, and a simple weight for height index which was used in the past and does not consider a child's age ${ }^{[6,7]}$. Obesity in children is defined using percentiles of BMI in growth reference charts. Children's BMI is classified as overweight or obese utilizing thresholds that change according to child's age and sex ${ }^{[8]}$. Beverages with artificial sweeteners gained popularity as substitutes to regular soft drinks, sugar sweetened juices and energy drinks ${ }^{[9]}$. However, the role of artificial sugars added to beverages as healthy alternatives have been very controversial ${ }^{[10]}$. Findings from systematic reviews and metaanalysis have shown a close association between artificial sweeteners and metabolic derangements among children leading to the increase in BMI and waist circumferences

Arshad MB, Seikh MU, Afazal M, Amjad A, Patoli S, Salahuddin MB. Association between artificially sweetened beverages consumption and changes in body mass index among children. Journal of University Medical \& Dental College. 2022; 
[11]. The main contributors towards increased consumption of sugars and artificial sweeteners are addictive behaviors as sugar packed foods and drinks are more palatable, fulfilling and satisfying ${ }^{[12]}$. However, it is pertinent to mention that where observational and cross-sectional studies have shown hefty associations between artificial sweeteners and obesity, randomized controlled trials didn't find any significant causal relationship between the two ${ }^{[13,14]}$. This research was aimed to look into the controversial role of Artificially Sweetened Beverages (ASB) in increasing/decreasing BMI among growing children of the UK.

\section{METHODOLOGY}

Our study performed secondary analysis of data from Millennium Cohort Study (MCS). The MCS is a prospective cohort study of UK children, following the lives of over 19,000 children born from 1st September 2000 till 31st August 2001 in Wales and England, and from 23rd November 2000 till 11th January 2002 in Northern Ireland and Scotland. Ethical clearance from Research Ethical Committee (REC) was obtained for both the pilot surveys and the main surveys. The data were retrieved for secondary analysis from the UK Data Service. This data is freely available for academic use, which does not require additional permission for that purpose. According to the Copyright, Designs and Patents Act 1988 UK, original literary work is protected by copyrights, while this study is done on data from MCS, which is made public and isn't governed by copyrights ${ }^{[15]}$. This study included the data from 5th sweep of MCS when the children were at the age of 11 . The sample size of MCS was 13,469 but after the removal of missing values, total number of study participants was 13,287. Respondents' BMI was the outcome variable which is a continuous variable. The beverages consumed by the respondents were largely comprised of containing artificial sweeteners like Aspartame, Saccharin and Sucralose. The frequency of ASB consumption was the exposure (Independent Variable) which had 7 categories: More than once a day, once a day, 3-6 days a week, 1-2 days a week, less often but at least once a month, less than once a month, never. Gender, child age, ethnicity, income quintiles, maternal education level and physical activity of cohort members were taken as covariates. Taking BMI (continuous variable) as main outcome variable, a linear regression was conducted to see the impact of variables independently. Adjustment of all covariates was carried out in linear regression analysis. The regression analysis was conducted using survey weights to account for the complex sampling design. Statistical analysis was done using STATA 12.0, and the significance level was set at $5 \%$ (p-value $<0.05)$ for the statistical analysis.

\section{RESULTS}

The sample characteristics are shown in Table-I of 13,287 total participants, $51 \%$ were males. The mean BMI of the cohort members in the sample was $19.25 \mathrm{~kg} / \mathrm{m} 2$. About $20 \%$ of the participants reported that they never consumed ASB in their lives. However, $21 \%$ of the participants reported the highest frequency of ASB consumption i.e., more than once
Table-I: Characteristics of study participants

\begin{tabular}{|c|c|}
\hline Total Observations: N: 13,287 Variable & $\mathrm{n}(\%)$ \\
\hline \multicolumn{2}{|l|}{ Gender } \\
\hline Male & $6,713(50.52)$ \\
\hline Female & $6,574(49.48)$ \\
\hline Missing & 0 \\
\hline \multicolumn{2}{|l|}{ ASB Consumption } \\
\hline Never & $2,654(19.97)$ \\
\hline$<$ Once a month & $860(6.47)$ \\
\hline Once a month at least & $1,074(8.08)$ \\
\hline 1-2 days/week & $1,900(14.30)$ \\
\hline 3-6 days/week & $1,135(8.54)$ \\
\hline Once a day & $2,268(17.07)$ \\
\hline$>$ Once a day & $2,743(20.64)$ \\
\hline Missing & $653(4.91)$ \\
\hline Child's BMI: Mean (S.D) & $19.25(3.68)$ \\
\hline \multicolumn{2}{|l|}{ Child's Age } \\
\hline 10 Years & $4,378(32.95)$ \\
\hline 11 Years & $8,843(66.55)$ \\
\hline 12 Years & $66(0.50)$ \\
\hline \multicolumn{2}{|l|}{ Mother's Education } \\
\hline Level 5 & $1,053(7.93)$ \\
\hline Level 4 & $3,627(27.30)$ \\
\hline Level 3 & $1,146(8.62)$ \\
\hline Level 2 & $3,883(29.22)$ \\
\hline Level 1 & $1,214(9.14)$ \\
\hline Overseas only & $449(3.83)$ \\
\hline None of above & $1,865(14.04)$ \\
\hline Missing & $50(0.38)$ \\
\hline \multicolumn{2}{|l|}{ Child Ethnicity } \\
\hline White & $10,992(82.73)$ \\
\hline Mixed & $383(2.88)$ \\
\hline
\end{tabular}

per day.

Table-II shows linear regression analysis of the association between ASB consumption and BMI.

The analysis adjusted the association for socioeconomic, demographic variables and confounding factors i.e., frequency of physical activity. Linear regression analysis showed the significant increase in BMI as the frequency of ASB consumption increases, with the increase of 1.06 $\mathrm{Kg} / \mathrm{m} 2$ (CI: 0.83-1.30, P-Value: $<0.001$ ) of BMI with the highest frequency of ASB consumption i.e. More than once a day. On average, females had a higher BMI than males (0.40, CI 0.24-0.55). Black children also had significantly greater BMI compared to White children (1.48, CI: 0.802.16). Mothers' education and Parental social class appeared to be a non-significant factor against BMI increase. Poorer children tended to have a higher BMI: the BMI increased in a linear fashion from the top quintile to the 4th quintile of household income. However, the BMI of children in the bottom quintile did not differ significantly from those in the top quintile. The analysis also exhibited that less than one 
Arshad MB, Seikh MU, Afazal M, et al.,

Table-II: Linear Regression analysis of ASB consumption and BMI.

(Number of observations after dropping the missing values from included variables=12,205).

\begin{tabular}{|c|c|}
\hline Variables & Model-A \\
\hline & Coef. ( $95 \% \mathrm{CI})$ \\
\hline \multicolumn{2}{|l|}{ ASB Consumption } \\
\hline Never & Ref Coef \\
\hline$<$ Once a month & $-0.08(-0.40-0.24)$ \\
\hline Once a month & $0.39(0.14-0.65) * *$ \\
\hline 1-2 days/week & $0.69(0.41-0.96) * * *$ \\
\hline 3-6 days/week & $0.77(0.47-1.07) * * *$ \\
\hline Once a day & $0.68(0.44-0.93) * * *$ \\
\hline$>$ Once a day & $1.06(0.83-1.30) * * *$ \\
\hline \multicolumn{2}{|l|}{ Sex } \\
\hline Male & Ref Coef. \\
\hline Female & $0.40(0.24-0.55) * * *$ \\
\hline \multicolumn{2}{|l|}{ Child age } \\
\hline 10 Years & Ref Coef. \\
\hline 11 Years & $0.22(0.06-0.39) * *$ \\
\hline 12 Years & $1.20(0.09-2.32) *$ \\
\hline \multicolumn{2}{|l|}{ Mother's Education } \\
\hline Level 5 & Ref Coef. \\
\hline Level 4 & $-0.12(-0.38-0.14)$ \\
\hline Level 3 & $-0.04(-0.38-0.29)$ \\
\hline Level 2 & $0.31(-0.01-0.64)$ \\
\hline Level 1 & $0.39(-0.02-0.80)$ \\
\hline Overseas only & $0.40(-0.08-0.89)$ \\
\hline None of above & $0.41(-0.03-0.85)$ \\
\hline \multicolumn{2}{|l|}{ Child's Ethnicity } \\
\hline White & Ref Coef. \\
\hline Mixed & $0.54(0.01-1.08)$ \\
\hline Indian & $-0.03(-0.50-0.43)$ \\
\hline Pakistani \& Bangladeshi & $0.37(0.08-0.67) *$ \\
\hline Black & $1.48(0.80-2.16) * * *$ \\
\hline Other Ethnic groups & $-0.56(-1.36-0.25)$ \\
\hline \multicolumn{2}{|l|}{ Equivalised Income Quintiles } \\
\hline Top Quintile & Ref Coef. \\
\hline 2nd Quintile & $0.05(-0.16-0.27)$ \\
\hline 3rd Quintile & $0.29(0.05-0.53) *$ \\
\hline 4th Quintile & $0.45(0.17-0.72) * * *$ \\
\hline Bottom Quintile & $-0.15(-0.48-0.18)$ \\
\hline \multicolumn{2}{|l|}{ Parental Social Class } \\
\hline Managerial \& Professional & Ref Coef. \\
\hline Intermediate & $-0.13(-0.37-0.11)$ \\
\hline Small employer & $0.20(-0.18-0.58)$ \\
\hline Low Supervisory \& Technical & $-0.03(-0.62-0.56)$ \\
\hline Semi-routine \& Routine & $0.05(-0.20-0.30)$ \\
\hline Missing & $0.07(-0.14-0.28)$ \\
\hline \multicolumn{2}{|l|}{ Frequency of Physical Activity } \\
\hline 5 or more days/week & Ref Coef. \\
\hline 4 days/week & $-0.11(-0.46-0.24)$ \\
\hline 3 days/week & $-0.03(-0.34-0.27)$ \\
\hline 2 days/week & $0.17(-0.11-0.45)$ \\
\hline
\end{tabular}


Table continued.

\begin{tabular}{lc}
1 day/week & $0.41(0.13-0.69)^{* *}$ \\
Never & $0.36(0.05-0.67)^{* *}$ \\
Constant & $17.28(16.88-17.68)^{* * *}$ \\
\hline
\end{tabular}

$* \mathrm{p}<0.05 \quad * * \mathrm{p}<0.01 \quad * * * \mathrm{p}<0.001$

day of physical activity per week was associated with higher BMI as compared to the activity of 5 or more days $(0.36, \mathrm{CI}$ : 0.05-0.67).

\section{DISCUSSION}

This study performed secondary analysis of data to contemplate an association between frequency of consumption of artificially sweetened beverages and its effects on BMI of UK children and provided evidence of an association between the two factors.

In line with these findings, the BMI of children consuming ASB more than once a day was increased by $1.11 \mathrm{~kg} /$ $\mathrm{m} 2$ compared to children who did not consume ASB's in the fully adjusted model. This very trend among children has previously been noted among past studies ${ }^{[16,17,18]}$. This association between frequent consumption of ASB and higher BMI among children can be explained by the decreased satiety and altered glucose homeostasis caused by ingredients used in beverages such as Aspartame and Saccharin ${ }^{[19,20]}$. Previously done studies also have attributed the association between ASP consumption and BMI increase to various plausible behavioral and psychological phenomenon indicating appetite enhancement consequent to sweet taste dissociation from caloric consumption. This ultimately leads to increased consumption of food and weight gain ${ }^{[21]}$. Additionally, poor diet quality is also considered to trigger the increased uptake of added caloric sweeteners ${ }^{[22]}$. The impact of equivalized family income showed an interesting trend. The risk of having greater BMI increased proportionally from the top to the 4th income quintile. However, children in the bottom quintile did not have a higher risk than children in the top quintile. Similar trends were detected in Health Survey for England 2016 where top income quintiles were least likely to be obese, but bottom quintiles showed a little deviation from the trend ${ }^{[23]}$.

The Strengths of this study are as follows. The strengths of this study were a large sample size from Millennium cohort study sweep 5 that comprised of nationally representative data of UK children and standardization of sampling methods by incorporation of statistical weights to equalize the representation from all regions of the country. The element of cross-sectional observational design was one of the weaknesses of this study. Further experimental investigation is recommended to look into the association between ASBs' consumption and BMI not only among children but also among adults.

\section{CONCLUSION}

This study concluded that a strong positive association between the frequency of artificially sweetened beverages and BMI increase was found among UK children in in Millennium Cohort Study. Maternal education and frequency of physical activity were found protective factors against the increase in BMI of UK children.

ACKNOWLEDGEMENT: None. CONFLICT OF INTEREST: None.

GRANT SUPPORT \& FINANCIAL DISCLOSURE: None.

\section{REFERENCES}

1. Engin A. The definition and prevalence of obesity and metabolic syndrome. Obesity and Lipotoxicity. 2017:17.

2. Meldrum DR, Morris MA, Gambone JC. Obesity pandemic: causes, consequences, and solutionsbut do we have the will?. Fertility and Sterility. 2017;107(4):833-839.

3. Ghanemi A, Yoshioka M, St-Amand J. Will an obesity pandemic replace the coronavirus disease-2019 (COVID-19) pandemic? Medical Hypotheses. 2020; 144:110042.

4. Reilly JJ, El-Hamdouchi A, Diouf A, Monyeki A, Somda SA. Determining the worldwide prevalence of obesity. The Lancet. 2018;391(10132):1773-1774.

5. Weir CB, Jan A. BMI classification percentile and cut off points. 2020.

6. Jayawardene W, Dickinson S, Lohrmann D, Agley J. Arm circumference-to-height ratio as a situational alternative to bmi percentile in assessing obesity and cardiometabolic risk in adolescents. Journal of obesity. 2018.

7. Yeager LJ, Karp SM. Barriers to the Implementation of Pediatric Overweight and Obesity Guidelines in a School-Based Health Center. The Nursing clinics of North America. 2019;54(1):159-168.

8. Costa-Urrutia P, Vizuet-Gámez A, Ramirez-Alcántara M, Guillen-González MÁ, Medina-Contreras O, ValdesMoreno M, et al. Obesity measured as percent body fat, relationship with body mass index, and percentile curves for Mexican pediatric population. PLoS One. 2019;14(2):e0212792.

9. Ruanpeng D, Thongprayoon C, Cheungpasitporn W, Harindhanavudhi T. Sugar and artificially sweetened beverages linked to obesity: a systematic review and meta-analysis. QJM: An International Journal of Medicine. 2017;110(8):513-520. Doi:10.1093/qjmed/ hcx068 
10. Durán Agüero S, Angarita Davila L, Escobar Contreras M, Rojas Gomez D, de Assis Costa J. Noncaloric sweeteners in children: A controversial theme. BioMed Research International. 2018.

11. Mallu MR, Naredla K, Meesala ML, Karyamsetty KV, Dudekula S, Boppa H, et al. Artificial Sweeteners and Metabolic Syndrome: Paradox of Physiological Behavior or Neuroendocrine Mechanisms. Journal of Pharmaceutical Research International. 2020:85-93. Doi: 10.9734/jpri/2020/v32i3330953

12. Stanner SA, Spiro A. Public health rationale for reducing sugar: Strategies and challenges. Nutrition Bulletin. 2020;45(3):253-270. Doi: 10.1111/nbu.12460

13. Rogers PJ, Hogenkamp PS, de Graaf C, Higgs S, Lluch A, Ness AR, et al. Does low-energy sweetener consumption affect energy intake and body weight? A systematic review, including meta-analyses, of the evidence from human and animal studies. International Journal of Obesity. 2016;40(3):381-394.

14. Toews I, Lohner S, de Gaudry DK, Sommer H, Meerpohl JJ. Association between intake of non-sugar sweeteners and health outcomes: systematic review and meta-analyses of randomised and non-randomised controlled trials and observational studies. BMI. 2019;364. Doi:10.1136/bmj.k4718

15. UK Data Service. Copyright [Internet]. UK Data Service. 2021 [cited 2021Oct29]. Available from: https:/ukdataservice.ac.uk/learning-hub/research-datamanagement/rights-in-data/copyright/

16. Luger M, Lafontan M, Bes-Rastrollo M, Winzer E, Yumuk V, Farpour-Lambert N. Sugar-sweetened beverages and weight gain in children and adults: a systematic review from 2013 to 2015 and a comparison with previous studies. Obesity Facts. 2017;10(6):674693.

17. Majeed A, Iqbal A, Masood Z, Malik A, Rehman HU, Ullah F, Ullah B, Nadir M. Correlation of Obesity to Daily Diet Intake of Young Girls of Quetta City, Pakistan. World Journal of Zoology. 2015;10(2):54-58.

18. Romo-Romo A, Aguilar-Salinas CA, Brito-Córdova GX, Gómez Díaz RA, Vilchis Valentín D, AlmedaValdes P. Effects of the non-nutritive sweeteners on glucose metabolism and appetite regulating hormones: systematic review of observational prospective studies and clinical trials. PloS one. 2016;11(8):e0161264.

19. Pearlman M, Obert J, Casey L. The association between artificial sweeteners and obesity. Current gastroenterology reports. 2017;19(12):64. Doi:10.1007/ s11894-017-0602-9

20. Jensen PN, Howard BV, Best LG, O'Leary M, Devereux RB, Cole SA, et al. Associations of diet soda and non-caloric artificial sweetener use with markers of glucose and insulin homeostasis and incident diabetes: the Strong Heart Family Study. European Journal of Clinical Nutrition. 2020;74(2):322-327. Doi:10.1038/ s41430-019-0461-6
21. Green E, Murphy C. Altered processing of sweet taste in the brain of diet soda drinkers. Physiology \& Behavior. 2012;107(4):560-567. Doi: 10.1016/j. physbeh.2012.05.006

22. Rusmevichientong P, Mitra S, McEligot AJ, Navajas E. The association between types of soda consumption and overall diet quality: evidence from National Health and Nutrition Examination Survey (NHANES). Californian Journal of Health Promotion. 2018;16(1):24-35.

23. Conolly A, Saunders C, Neave A. Health Survey for England 2016: adult overweight and obesity. Health and Social Care Information Centre. 2017.

\section{Author's Contribution:}

Muhammad Bilal Arshad: Conception, design, and acquisition of data.

Muhammad Usman Sheikh: Statistical analysis and interpretation of data.

Muhammad Afzal: Critical review of article and methodology.

Aneela Amjad: Data compilation and manuscript drafting.

Shahzeb Patoli: Acquisition of data and literature review.

Muhammad Behzad Salahuddin: Manuscript drafting and final approval of the version.

Submitted for publication: 23-10-2021

Accepted after revision: 27-01-2022 